\title{
Accidental injury: risk and preventative interventions
}

Ingeborg van Weeghel, Denise Kendrick, Patricia Marsh

\begin{abstract}
Objective-To evaluate the relation between risk factors for childhood unintentional injury and requests for injury prevention interventions as part of the Nottingham Safe at Home project, a primary care based controlled intervention study assessing the effectiveness of a package of injury prevention interventions.

Setting-17 practices in Nottingham randomly selected from 55 practices volunteering to take part in the study.

Methods-Postal questionnaire to all parents of children aged 3 to 12 months registered with the intervention practices $(n=$ 1124) to assess risk factors for injury and to elicit requests for three injury prevention interventions: free home safety checks, low cost safety equipment, and free first aid training.

Results $-73 \%$ of parents responded to the questionnaire. The distribution of sociodemographic variables among responders was similar to that for the population of Nottingham. One third of parents (34\%) requested one intervention, $21 \%$ requested two interventions, and $10 \%$ requested three. Receipt of means tested benefits, ethnicity, and residence in a deprived area were independently associated with requesting home safety checks. Non-owner occupation, lack of access to a car, receipt of means tested benefits, ethnicity, and unemployment were independently associated with requesting low cost safety equipment. Non-owner occupiers were less likely to request first aid training.

Conclusions-Families with risk factors for childhood unintentional injury do request home safety checks and low cost safety equipment, but they are less likely to request first aid training. Other methods for providing first aid advice may be needed to reach such families.

(Arch Dis Child 1997;77:28-31)
\end{abstract}

Keywords: unintentional injury; injury prevention; risk factors

Deneral Pract

D Kendrick

Department of Public

Health Medicine and

Epidemiology

P Marsh

Correspondence to:

Dr Kendrick.

Accepted 16 April 1997 factors, for example male sex, family size and type, socioeconomic disadvantage, maternal age, and previous medically attended injury. ${ }^{1-11}$ The sensitivity of some of these factors in identifying which children will go on to have injuries has been shown to be relatively low. ${ }^{1}$ However, if injury prevention programmes only reach those children at least risk, the potential for programmes to reduce injury rates and hence to prove their effectiveness will be limited.

Previous studies have most often assessed the uptake of preventive child health care by considering immunisation rates and attendance at child health clinics. The uptake of child immunisation has been found to be associated with socioeconomic disadvantage, several studies having shown lower immunisation rates and a later median immunisation date from birth among children living in disadvantaged circumstances. ${ }^{12-14}$ Attendance at child health clinics has been found to be associated with maternal age, young mothers being more frequent attenders and mothers aged 36 years or more often being non-attenders. ${ }^{15}$ The association with socioeconomic deprivation is less clear, though in one study higher attendance rates were found among families living in poorer circumstances, as defined by father's occupation, and in those living in non-owned accommodation. ${ }^{15}$ However, three other studies failed to confirm this finding: one found lower clinic attendance rates in children from disadvantaged families based on father's occupation $^{16}$ and two failed to find any association (one of these used an area based measure of deprivation, ${ }^{17}$ and the other used father's occupation $^{18}$ ). When general practitioner run clinics were analysed separately, disadvantaged mothers were significantly less likely to attend such clinics compared with other mothers. ${ }^{18}$

There is some published work examining the uptake of childhood injury prevention services among disadvantaged families. Eichelberger and colleagues ${ }^{19}$ found that a higher proportion of disadvantaged families expressed interest in safety information. Roberts ${ }^{20}$ found that parents from disadvantaged groups were less likely to respond to a petition calling for road safety measures, despite their children being at greater risk of pedestrian injury. Roberts and colleagues, in their work with disadvantaged families in Glasgow, found families were aware of the risks their children faced, already undertook many 'safety routines' to keep their children safe, and participated in injury prevention in their community. ${ }^{21}$ 
Table 1 Frequency of risk factors for childhood unintentional injury (\%)

\begin{tabular}{lc}
\hline Risk factor & Frequency (\%) \\
\hline Four or more children & $55(6.7)$ \\
Single parent & $89(10.8)$ \\
Teenage mother & $114(13.9)$ \\
Non-owner occupation & $231(28.1)$ \\
Lack of access to car & $149(18.1)$ \\
Receipt of means tested benefits & $246(29.9)$ \\
Overcrowding & $64(7.8)$ \\
Ethnic group non-white & $52(6.3)$ \\
Residence in deprived area† & $94(11.4)$ \\
Previous medically attended unintentional injury & $42(5.1)$ \\
Unemployment: & $73(8.9)$ \\
One parent unemployed in two parent family & $22(2.7)$ \\
Single parent or both parents in two parent family unemployed & \\
\hline
\end{tabular}

$\bar{\star}$ Overcrowding defined as more than one person per room excluding bathrooms and kitchens less than $2 \mathrm{~m}$ wide.

†Residence in a deprived area defined as living in a ward with a Jarman score in the most deprived quartile of scores for all respondents (Jarman score 36.48 to 51.1).

The study reported here was undertaken to examine the relation between risk factors for childhood unintentional injury and willingness to participate in a primary care based injury prevention programme. The Nottingham Safe at Home project is ongoing and results of the effectiveness of the interventions will be presented at a later date.

\section{Methods}

A postal questionnaire survey was undertaken as part of the baseline data collection for the Nottingham Safe at Home project. This is a primary care based childhood injury prevention intervention study. All health visitors in Nottingham were approached to take part in the study. Of the 55 health visitors responding positively, 22 were randomly chosen for the intervention group, from 17 practices. This number of practices was chosen since sample size calculations undertaken for testing the hypothesis of the main study - on the effectiveness of injury prevention interventionsindicated that 17 practices in both the intervention and control groups would give the study $90 \%$ power at the $5 \%$ significance level of detecting a reduction in injury frequency of $5 \%$, based on an estimated mean injury rate of $25 \%$ in the control group.

All parents or guardians of children aged between 3 and 12 months registered with the 17 practices comprised the population for the study reported here $(n=1124)$. A questionnaire was designed to assess risk factors for injury, safety practices, perceptions of risk of injury and of risk of hazards, and knowledge and confidence in dealing with first aid. This

Table 2 Types of injury prevention interventions requested by responders $(n=823)$ to the questionnaire (\%)

\begin{tabular}{lc}
\hline Injury prevention interventions & $\begin{array}{c}\text { Frequency of requested } \\
\text { interventions (\%) }\end{array}$ \\
\hline $\begin{array}{l}\text { First aid training only } \\
\text { Low cost safety equipment only }\end{array}$ & $230(27.9)$ \\
$\begin{array}{l}\text { Home safety checks only } \\
\text { First aid training and home safety } \\
\quad \text { checks }\end{array}$ & $10(1.9)$ \\
$\begin{array}{l}\text { First aid training and safety } \\
\text { equipment }\end{array}$ & $88(10.7)$ \\
$\begin{array}{l}\text { Safety equipment and home safety } \\
\text { checks }\end{array}$ & $68(8.3)$ \\
$\begin{array}{l}\text { All three interventions } \\
\text { Total number of respondents } \\
\text { requesting intervention }\end{array}$ & $18(2.2)$ \\
\hline
\end{tabular}

study is only concerned with the section of the questionnaire on risk factors, so other sections will not be considered further. The questions on risk factors were obtained from a questionnaire previously designed by the authors, which had been found to have acceptable reliability with $\kappa$ coefficients for all risk factor questions ranging from 0.87 to $1.00 .^{22}$ Content validity was assured by including all risk and sociodemographic factors found in published reports to be associated with childhood unintentional injury. ${ }^{1-11}$

The questionnaire was mailed to the parents or guardians of all children aged 3 to 12 months registered at each of the 17 practices, with a covering letter signed by the child's general practitioner and invitations for free home safety checks to be carried out by the health visitor, low cost safety equipment and free first aid training to be carried out by the practice nurse or health visitor. Parents were asked to complete and return invitations for those interventions they wished to participate in. Nonresponders were sent a postcard reminder after two weeks, and a second questionnaire was sent to parents still not responding after a further two weeks. Health visitors identified families on their caseload for whom English was not their first language and whom they considered might need help in interpreting the questionnaire. Trained interpreters from the local community health trust were used to carry out structured interviews with these families using the same questionnaire.

The questionnaires were precoded and data were entered into the EPI-INFO package and verified by repeated entry. Data were imported into and analysed using the SPSS-PC package. Deprivation was measured at the ward level by the Jarman score. ${ }^{23}$ Categorical variables were analysed using $\chi^{2}$ tests and continuous variables using Mann-Whitney $U$ and KruksalWallis tests. Logistic and multiple linear regression analyses were undertaken to assess the independent effects of the risk factors on requesting each type of intervention and on the number of interventions requested respectively.

\section{Results}

A total of 1124 questionnaires was sent, of which 823 were returned and completed $(73 \%)$. The distribution of risk factors among responders is shown in table 1, 537 parents $(65 \%)$ requesting at least one injury prevention intervention. The frequency of requests for each of the interventions is shown in table 2 . Univariate analyses showed that many of the risk factors were associated with requesting home safety checks and low cost safety equipment, but that only housing tenure and young maternal age were associated with requesting first aid training. These results are summarised in table 3. After adjusting for the confounding effects of other risk factors, ethnicity, receipt of means tested benefits, and residence in a deprived area were independently associated with requesting home safety checks. Ethnicity, housing tenure, car ownership, receipt of means tested benefits, and 
Table 3 Significance levels for univariate analyses of risk factors associated with requests for each of the injury prevention interventions

\begin{tabular}{llll}
\hline Risk factor & $\begin{array}{l}\text { Home safety } \\
\text { checks }\end{array}$ & $\begin{array}{l}\text { Low cost safety } \\
\text { equipment }\end{array}$ & First aid training \\
\hline Four or more children & $\mathrm{NS}$ & $\mathrm{p}<0.001$ & $\mathrm{NS}$ \\
Single parent & $\mathrm{p}<0.001$ & $\mathrm{p}<0.001$ & $\mathrm{NS}$ \\
Teenage mother & $\mathrm{NS}$ & $\mathrm{p}<0.001$ & $\mathrm{p}<0.05$ \\
Non-owner occupation & $\mathrm{p}<0.05$ & $\mathrm{p}<0.01$ \\
Lack of access to a car & $\mathrm{p}<0.001$ & $\mathrm{p}<0.001$ & $\mathrm{NS}$ \\
Receipt of means tested benefits & $\mathrm{p}<0.01$ & $\mathrm{p}<0.001$ & $\mathrm{NS}$ \\
Overcrowding & $\mathrm{NS}$ & $\mathrm{p}<0.001$ & $\mathrm{NS}$ \\
Ethnic group non-white & $\mathrm{p}<0.001$ & $\mathrm{p}<0.001$ & $\mathrm{NS}$ \\
Residence in a deprived area & $\mathrm{NS}$ & $\mathrm{NS}$ & $\mathrm{NS}$ \\
Previous medically attended injury & $\mathrm{NS}$ & $\mathrm{p}<0.001$ & $\mathrm{NS}$ \\
Unemployment & $\mathrm{NS}$ & &
\end{tabular}

*All analyses undertaken using $\chi^{2}$ tests with 1 degree of freedom, except for unemployment where there were 2 degrees of freedom and residence in a deprived area where there were 3 degrees of freedom.

Table 4 Independent associations between risk factors for childhood unintentional injury and requests for injury prevention interventions

\begin{tabular}{lll}
\hline Risk factor & $\begin{array}{l}\text { Odds } \\
\text { ratio }\end{array}$ & $\begin{array}{l}\text { 95\% Confidence } \\
\text { interval }\end{array}$ \\
\hline $\begin{array}{l}\text { Home safety checks } \\
\quad \text { Receipt of means tested benefits }\end{array}$ & 1.62 & 1.07 to 2.48 \\
$\quad$ Ethnic group non-white & 4.52 & 1.99 to 10.28 \\
$\quad$ Residence in deprived area & 3.11 & 1.48 to 6.54 \\
$\quad$ Low cost safety equipment & & \\
$\quad$ Non-owner occupation & 2.94 & 1.72 to 5.03 \\
$\quad$ Lack of access to a car & 2.13 & 1.21 to 3.75 \\
$\quad$ Receipt of means tested benefits & 3.73 & 2.22 to 6.26 \\
$\quad$ Ethnic group non-white & 3.17 & 1.28 to 7.87 \\
$\quad$ Unemployment & 2.77 & 1.41 to 5.46 \\
$\quad \begin{array}{l}\text { First aid training } \\
\quad \text { Non-owner occupation }\end{array}$ & 0.53 & 0.34 to 0.83 \\
\hline
\end{tabular}

$\star$ Unemployment defined as single parent unemployed, or both parents unemployed in a two parents family.

unemployment were independently associated with requesting low cost safety equipment. Only housing tenure remained independently associated with requesting first aid training. These results are shown in table 4. Families receiving means tested benefits, without access to a car, and classifying themselves as belonging to an ethnic group other than white were predicted by the linear regression model to request two interventions, whereas families without those risk factors were predicted to request one intervention.

\section{Discussion}

In this study we have shown that families with risk factors for childhood unintentional injury, including socioeconomic disadvantage, are more likely to request home safety checks and low cost safety equipment than families without risk factors. Families living in nonowner accommodation were less likely to request first aid training than families owning their homes, but none of the other risk factors was associated with requesting first aid training.

Comparisons of the prevalence of sociodemographic variables in responders to the questionnaire suggests that responders were similar to the general population of Nottingham in terms of the prevalence of unemployment, non-owner occupation, ethnicity, and overcrowding, but that the percentage of respondents who were single parents and who did not have access to a car was smaller. ${ }^{24}$ It is therefore possible that the odds ratio for requesting low cost safety equipment in families without access to a car represents an overestimate of the true odds ratio if all non-car owning families had responded and did not request safety equipment. As most of the significant odds ratios were found for the risk factors which were not underrepresented among respondents, it seems unlikely that response bias can explain our results.

The finding that families with risk factors for childhood injury do request home safety checks and low cost safety equipment is encouraging for injury prevention programmes offering such interventions. Requesting such interventions is only one of the steps for these families in practising injury prevention. Compliance with the interventions is important if they are to be effective. Previous studies have shown that low income families will use free or loaned infant car seats ${ }^{25} 26$ and that families at higher risk of house fires will install and maintain free smoke alarms in an operational condition. ${ }^{27}$ Uptake of the interventions in the Safe at Home project so far supports these findings, with more than $75 \%$ of families requesting home safety checks or low cost safety equipment having received the requested interventions after one year of the two year intervention period.

Why do families with risk factors for childhood injury disproportionately request home safety checks and low cost safety equipment? Previous work has suggested that parents from families with risk factors for childhood injury live in homes containing more hazards than families without such risk factors. ${ }^{28-30}$ Comparisons of perceptions of risk suggest that parents from low income families perceive injuries to be more likely and more serious and home hazards to be more likely and more dangerous. ${ }^{21}{ }^{31}$ Roberts and colleagues', working in a disadvantaged area in Glasgow, showed that parents could identify the risks faced by their children and that many parents were already taking action to keep their children safe in hazardous situations. Similarly a recent survey in Scotland showed that parents in less affluent areas held similar attitudes to home safety but reported more safety practices than parents in more affluent areas. ${ }^{32}$ It is therefore understandable that families with risk factors for unintentional injury are more likely to request injury prevention interventions.

In terms of injury prevention practice, an educational campaign aimed at raising awareness of risk of injury is unlikely to be successful in such families, as lack of awareness is not the factor limiting injury prevention practice. This awareness of risk also has important implications for the way in which injury prevention is delivered. Health care workers need to acknowledge that the family is aware of the risks and will already be taking action to keep their children safe. Building on this, health care workers can explore with the family the risks they are most concerned about, the action the family has already taken, the barriers preventing the family from further addressing those risks, and they can identify support they can offer the family. 
The association between requesting first aid training and owner occupation is interesting, as it suggests that high risk families are less interested in, or less able to take advantage of, a primarily educational intervention. The training is free and is offered in local community settings with a free crèche provided for child care, in order to minimise the potential difficulties for parents in attending such a session. The findings from our study suggest either that families at high risk do not want information on first aid, or that this is not an acceptable method of providing the information for such families. Previous work suggested that parents do want information on first aid, ${ }^{19} 2133$ including families at high risk of injury. ${ }^{19}$ Bearing this in mind, other methods for providing such information in future injury prevention programmes should be considered-for example, making use of existing antenatal, postnatal, or mother and toddler groups, giving individualised advice as part of the child health surveillance programme, giving opportunistic advice following childhood unintentional injuries, first aid training in schools, or mass media campaigns.

The interventions offered as part of the Safe at Home project have been successful in that home safety checks and low cost safety equipment are being requested by families most at risk of unintentional injury, but first aid training may not reach those most at risk if offered by the methods used in this study.

1 Bijur PE, Golding J, Haslum M. Persistence of occurrence of injury: can injuries of pre-school children predict injuries of injury: can injuries of pre-school children predict

2 Horwitz SM, Morgenstern H, DiPietro L, Morrison C. Determinants of pediatric injuries. Am $\mathfrak{f} \mathrm{Dis}$ Child 1988;142:605-11.

3 Bijur PE, Golding J, Haslum M, Kurzon M. Behavioural predictors of injury in school age children. Am $\mathcal{F}$ Dis Child 1988;142:1307-12.

4 Taylor B, Wadsworth J, Butler NR. Teenage mothering, admission to hospital and accidents during the first 5 years. Arch Dis Child 1983;58:6-11.

5 Roberts I. Sole parenthood and the risk of pedestrian injury. 7 Paediatr Child Health 1994;30:530-2.

6 Wadsworth J, Burnell I, Taylor B, Butler N. Family type and accidents in pre-school children. 7 Epidemiol Community Health 1983;37:100-4.

7 Bijur PE, Golding J, Kurzon M. Childhood accidents, family size and birth order. Soc Sci Med 1988;26:839-43.

8 Eminson CJ, Jones H, Goldacre M. Repetition of accidents in young children. $\mathcal{F}$ Epidemiol Community Health 1986;40: $170-3$.
9 Sellar C, Ferguson JA, Goldacre MJ. Occurrence and repetition of hospital admission for accidents in pre-school children. BMF 1991;302:16-9.

10 Boyce WT, Sobolewski RN. Recurrent injuries in school children. Am f Dis Child 1989;143:338-42.

11 Stewart-Brown S, Peters TJ, Golding J, Bijur P. Case definition in childhood accident studies: a vital factor in determining results. Int ₹ Epidemiol 1986;15:352-9.

12 Marsh GN, Channing DM. Deprivation and health in one general practice. BMF 1986;292:1173-6.

13 Jarman BJ, Bosenquet N, Rice P, Dollimore N, Leese B. Uptake of immunisation in district health authorities in England. BMF 1988;296:1775-8.

14 Adjaye N. Measles immunisation-some factors affecting non-acceptance of vaccine. Public Health 1981;95:185-8.

15 While A. Child health clinic attendance during the first two years of life. Public Health 1986;100:156-65.

16 Zinkin PM, Cox CA. Child health clinics and inverse care laws: evidence from longitudinal study of 1878 pre-school children. BMF 1976;ii:411-3.

17 Morgan M, Reynolds A, Morris R, Allsop M, Rona R. Who uses child health clinics and why? A study of deprived inner city district. Health Visitor 1989;62:244-7.

18 Moss P, Bolland G, Foxman R, Owen C. The first six months after birth: mother's views of health visitors. Health Visitor 1986;59:71-4.

19 Eichelberger MR, Gotschall CS, Feely HB, Harstad P, Bowman LM. Parental attitudes and knowledge of child safety. Am f Dis Child 1990;144:714-20.

20 Roberts I. Who's prepared for advocacy? Another inverse law. Injury Prev 1995;1:152-4.

21 Roberts H, Smith SJ, Bryce C. Children at risk? Safety as a social value. Buckingham: Open University Press, 1995.

22 Woods A, Kendrick D, Rushton L. Safety practices among parents and children in a primary care setting. Health Educ f 1994;53:397-408.

23 Jarman B. Identification of underprivileged areas. BMF 1983;286:1705-9.

24 Office of Population Censuses and Surveys. 1991 Census. County report: Nottinghamshire (part 1). London: HMSO, 1993.

25 Robitaille Y, Legault J, Abbey H, Pless IB. Evaluation of an infant car seat program in a low income community. $A m \mathcal{F}$ Dis Child 1990;144:74-8.

26 Berger LR, Saunders S, Armitage K, Schauer L. Promoting the use of car safety devices for infants: an intensive health education approach. Pediatrics 1984;74:16-9.

27 Gorman RL, Charney E, Holtzman NA, Roberts KB. A successful city-wide smoke detector give-away program. Pediatrics 1985;75:14-18.

28 Greaves P, Glik DC, Kronenfeld J, Jackson K. Determinants of controllable in-home child safety hazards. Health Educ Res Theory Pract 1994;9:307-15.

29 Santer LJ, Stocking CB. Safety practices and living conditions of low income urban families. Pediatrics 1991;88:1112-7.

30 Kendrick D. Children's safety in the home: parent's possession and perceptions of importance of safety equipment. Public Health 1994;108:21-5.

31 Glik D, Kronenfeld J, Jackson K. Predictors of risk perceptions of childhood injury among parents of pre-schoolers. Health Educ Q 1991;18:285-301.

32 Evans SA, Kohli HS. Socioeconomic status and the prevention of child home injuries. Injury Prevention 1997;3:29-34.

33 Coombes G. You can't watch them twenty four hours a day. Parents' and children's perceptions, understanding and experience of accidents and accident prevention. London: Child Accident Prevention Trust, 1991. 